\title{
PRODUÇÃO DE MUDAS DE ABÓBORA COM DIFERENTES DOSES DE NITROGÊNIO E POTÁSSIO ( $\left.{ }^{\mathbf{1}}\right)$
}

\author{
ANDRÉA REIKO OLIVEIRA HIGUTI $\left({ }^{2}\right)$; ARIANE DA CUNHA SALATA $\left({ }^{2}\right)$; \\ AMANDA REGINA GODOY $\left({ }^{2}\right)$; ANTONIO ISMAEL INÁCIO CARDOSO $\left(2^{*}\right)$
}

\begin{abstract}
RESUMO
O experimento foi desenvolvido em ambiente protegido, em São Manuel (SP). O objetivo deste trabalho foi avaliar a produção de mudas de abóbora 'Menina Brasileira' em substrato à base de fibra de coco com diferentes doses de nitrogênio e potássio em fertirrigação. Utilizou-se o delineamento experimental em blocos ao acaso, com 16 tratamentos em esquema fatorial $4 \times 4$, sendo quatro doses de nitrogênio (0, 40, 80 e $120 \mathrm{mg} \mathrm{L}^{-1}$ de N) na forma de nitrato de amônio e quatro doses de potássio $\left(0,70,140\right.$ e $210 \mathrm{mg} \mathrm{L}^{-1}$ de $\mathrm{K}_{2} \mathrm{O}$ ) na forma de cloreto de potássio, em quatro repetições e dez plantas por parcela. As características avaliadas foram: massa fresca e seca da parte aérea e raiz, altura e número de folhas. As doses de potássio não influenciaram as características avaliadas. Houve, porém, aumento linear para a maioria das características avaliadas com doses crescentes de nitrogênio, exceto para a massa seca da raiz.
\end{abstract}

Palavras-chave: Cucurbita moschata, adubação, fibra de coco.

\section{ABSTRACT \\ PRODUCTION OF SQUASH SEEDLING WITH DIFFERENT NITROGEN AND POTASSIUM RATES}

The experiment was conducted under controlled condition, in São Manuel (SP). The objective of the present research was to evaluate the production of 'Menina Brasileira' squash seedling grown in coconut fiber substrate with varying availabities of nitrogen and potassium. Nutrients were applied via fertirrigation. The experimental design was in randomized blocks, with 16 treatments in a factorial $4 \mathrm{x}$ 4: four rates of nitrogen $\left(0,40,80\right.$ and $\left.120 \mathrm{mg} \mathrm{L}^{-1} \mathrm{~N}\right)$ as nitrate amonium and four rates of potassium $(0$, 70,140 and $210 \mathrm{mg} \mathrm{L}^{-1} \mathrm{~K}_{2} \mathrm{O}$ ) as potassium chloride. Four replicates and ten plants per plot were considered in this study. The characteristics evaluated in the seedlings were: fresh and dry mass of shoot and root, height and number of leaves. Potassium availability did not influence the evaluated characteristics. However, there was linear increase for most of characteristics with increasing rates of nitrogen, except for root dry mass.

Keywords: Cucurbita moschata, fertilization, coconut fiber.

$\left({ }^{1}\right)$ Recebido para publicação em 16 de março de 2009 e aceito em $1 .^{\circ}$ de outubro de 2009.

$\left({ }^{2}\right)$ Departamento Produção Vegetal, Faculdade de Ciências Agronômicas, Universidade Estadual Paulista, Caixa Postal 237, 18603-970 Botucatu (SP). E-mail: ismaeldh@fca.unesp.br $\left(^{*}\right)$ Autor correspondente. 
A produção de mudas consiste em uma das etapas mais importantes do sistema produtivo hortícola, necessitando utilização de insumos de alta qualidade (Silveira et al., 2002), sendo o substrato um dos insumos de maior importância na produção de mudas (CoRREIA et al., 2003). O manejo correto e o tipo de substrato agrícola exercem influência significativa na formação do sistema radicular de plantas e, portanto, podem interferir no estado nutricional (SPURR e BARNES, 1973).

Segundo Gonçalves (1995) e Gomes e Silva (2004), todo material natural ou artificial, puro ou em mistura, que colocado em recipiente que permita a fixação do sistema radicular, possibilitando suporte à planta, pode ser considerado um substrato agrícola.

Existem vários substratos para produção de mudas de hortaliças de diferentes marcas, com diferentes origens e diferentes características químicas e físicas, fazendo com que o manejo da adubação seja bastante complexo.

A fibra da casca do coco verde está se tornando matéria-prima importante na produção de substratos de boa qualidade para a produção de mudas ou em cultivos sem o uso do solo (MALVESTITI, 2004). A facilidade de produção, baixo custo e alta disponibilidade são algumas vantagens apresentadas por este tipo de substrato, além de ser produto renovável. No entanto, o substrato feito a partir das fibras de coco é pobre em nutrientes essenciais para as plantas. Portanto, é preciso fornecê-los de acordo com as necessidades da espécie a ser cultivada adicionando-se adubos em pré-plantio ou, principalmente, em fertirrigação (CARRIJO et al., 2002).

A fertirrigação consiste na aplicação de fertilizantes minerais com alta solubilidade em água, permitindo manter a disponibilidade de água e nutrientes próximos dos valores considerados ótimos ao crescimento e à produtividade da cultura (FERNANDES et al., 2002).

O nitrogênio e o potássio estão entre os nutrientes mais requeridos pelas culturas e, frequentemente, a resposta das plantas à adubação é mais dependente da interação entre esses elementos que do nutriente isolado (Malavolta et al., 1997). A deficiência de nitrogênio nas mudas compromete o desenvolvimento da planta e reduz o acúmulo de matéria seca. O potássio controla a turgidez do tecido, ativa enzimas envolvidas no processo da respiração, fotossíntese, transpiração, abertura e fechamento dos estômatos (MALAVOLTA, 1980).

As quantidades de nutrientes extraídas pelas plantas variam em função da espécie e do prazo para a formação da muda. O desempenho da muda também depende da quantidade de nutriente fornecida (CARMello, 1995).

Trabalhos que tratam de adubação na produção de mudas em substratos pobres em nutrientes, especialmente na fibra de coco, com bom desempenho como substrato para cultivo de hortaliças, são escassos. Assim, o presente trabalho objetivou avaliar a produção de mudas de abóbora 'Menina Brasileira' com diferentes doses de nitrogênio e potássio em substrato a base de fibra de coco.

O experimento foi instalado no município de São Manuel (SP), com coordenadas geográficas de $22^{\circ} 44^{\prime}$ de latitude sul, $48^{\circ} 34^{\prime}$ de longitude oeste de Greenwich e altitude média de $750 \mathrm{~m}$. O clima local é do tipo mesotérmico, Cwa, subtropical úmido, com presença de estiagem no período de inverno (EspíndolA et al., 1974).

O experimento foi desenvolvido sob ambiente protegido, em estrutura metálica tipo arco com dimensões de $7 \times 20$ metros e pé direito de 2,5 metros, coberta com filme de polietileno transparente de 150 $\mu \mathrm{m}$ de espessura. Nas laterais, tela antiafídeos fechando o ambiente.

A semeadura da abóbora 'Menina Brasileira' foi realizada em 19/11/2007 em bandejas de poliestireno expandido de 128 células, utilizando-se substrato Golden $\mathrm{Mix}^{\circledR}\left(\mathrm{N}=0,76 ; \mathrm{P}_{2} \mathrm{O}_{5}=0,34 ; \mathrm{K}_{2} \mathrm{O}=1,22\right.$; $\mathrm{Ca}=0,69 ; \mathrm{Mg}=0,25 ; \mathrm{S}=0,41 ; \mathrm{Um} .=21,30 ; \mathrm{M} . \mathrm{O} .=86,00$; $\mathrm{C}=47,80 \mathrm{em} \%$ na matéria seca e $\mathrm{Na}=500 ; \mathrm{Cu}=100$; $\mathrm{Fe}=2600 ; \mathrm{Mn}=266 ; \mathrm{Zn}=148 \mathrm{mg} \mathrm{kg}^{-1}$ matéria seca e C/ $\mathrm{N}=63 / 1 ; \mathrm{pH}=4,50$ ), composto por fibras do mesocarpo de cascas de coco. Procedeu-se o destorroamento do substrato, deixando-o bem solto. Foram adicionados 30 litros de água para 107 litros de substrato, ficando a mistura em repouso por 2 horas, antes de encher as bandejas.

Estudou-se a produção de mudas de abóbora em substrato à base de fibra de coco com diferentes doses de nitrogênio e potássio. Para tanto, os tratamentos consistiram de doses de nitrogênio e de potássio, tendo como fontes o nitrato de amônio (34\% de $\mathrm{N})$ e o cloreto de potássio $\left(60 \%\right.$ de $\left.\mathrm{K}_{2} \mathrm{O}\right)$. As doses utilizadas foram: zero; $40 ; 80$ e $120 \mathrm{mg} \mathrm{L}^{-1}$ de $\mathrm{N}$; e zero; $70 ; 140$ e $210 \mathrm{mg} \mathrm{L}^{-1}$ de $\mathrm{K}_{2} \mathrm{O}$. Junto com os tratamentos, em cada fertirrigação, foram aplicados cálcio, magnésio e fósforo $\left(60,50\right.$ e $\left.100 \mathrm{mg} \mathrm{L}^{-1}\right)$, utilizando-se cloreto de cálcio, sulfato de magnésio e superfosfato triplo respectivamente.

O delineamento experimental adotado foi o blocos ao acaso, com 16 tratamentos, em esquema fatorial $4 \times 4$, com quatro repetições. As parcelas foram constituídas por meia bandeja, 64 células, sendo avaliadas dez plantas centrais por parcela. As 
fertirrigações foram realizadas de 30/11/2007, início do desenvolvimento das plântulas, até 7/12/2007, quando atingiram o ponto de transplante, com duas folhas definitivas. As adubações foram realizadas em dias alternados, colocando-se $1000 \mathrm{~mL}$ da solução por bandeja, totalizando quatro fertirrigações.

Quando as mudas atingiram o ponto de transplante avaliaram-se as seguintes características: massa fresca da parte aérea e da raiz separadamente, valores obtidos através de pesagem em balança analítica com valores expressos em grama; altura da parte aérea, medida da base do hipocótilo até o ápice da muda, com auxílio de um paquímetro, valores expressos em centímetros; contagem do número de folhas; e massa seca da parte aérea e da raiz, onde as folhas + hastes e raízes da planta foram separadas e colocadas em estufa com circulação de ar forçada a $65^{\circ} \mathrm{C}$ até massa constante, valores obtidos através de pesagem em balança analítica com valores expressos em grama.

Realizou-se a análise de variância com teste F, e para as características em que foram observadas diferenças significativas, realizou-se a análise de regressão.

Apesar de Malavolta et al. (1997) destacarem que a resposta das plantas à adubação com nitrogênio e potássio, é mais dependente da interação entre esses elementos que de cada nutriente isoladamente, não se observou interação entre eles. Embora a fibra de coco seja pobre em nutrientes (CARRIJO et al., 2002) e o potássio seja um dos nutrientes mais extraídos pelas plantas (Malavolta, 1980), com a aplicação de doses crescentes de potássio não foram observadas diferenças significativas nas características avaliadas, com média de 17,0 g, 1,94 g, 7,21 cm, 2,5 folhas, $6,0 \mathrm{~g}$ e $0,36 \mathrm{~g}$ para a massa fresca da parte aérea, massa seca da parte aérea, altura, número de folhas, massa fresca da raiz e massa seca da raiz das mudas respectivamente.

Melton e Dufault (1991) relataram que as diferentes doses de potássio $\left(25,75\right.$ ou $\left.225 \mathrm{mg} \mathrm{L}^{-1}\right)$ aplicadas três vezes por semana não influenciaram altura, diâmetro, número de folhas, área foliar, massa fresca e seca das mudas de tomateiro.

Dufault (1985) estudou a aplicação de diferentes concentrações de $\mathrm{P}, \mathrm{K}$ e $\mathrm{N}$ na produção de mudas de salsão e também observou que o K $(10,50$ ou $250 \mathrm{mg} \mathrm{L}^{-1}$ ) não afetou as características avaliadas, talvez pelo seu teor inicial elevado no substrato. Soundy (1996) constatou que a aplicação de diferentes concentrações de potássio $\left(0 \mathrm{a} 60 \mathrm{mg} \mathrm{L}^{-1}\right)$ não afetou as características das mudas de alface quando utilizou o substrato à base de "turfa + vermiculita", porém houve aumento na massa de raiz e parte aérea das mudas quando o substrato era à base de "turfa + lã de rocha". Este resultado foi explicado pela disponibilização de potássio pela vermiculita no primeiro substrato. No substrato utilizado neste experimento o potássio era o nutriente encontrado em maior concentração $(1,22 \%$ na matéria seca), podendo explicar a ausência de diferença entre as doses. Porém, não existem padrões para substrato ao se afirmar se este teor é elevado, médio ou baixo.

No entanto, para as doses de nitrogênio podese verificar aumento linear nas características avaliadas (Figura 1), exceto para a massa seca da raiz, em que não houve diferença estatística, com média de $0,36 \mathrm{~g}$ por muda. Em média, para cada $10 \mathrm{mg}$ de $\mathrm{N} \mathrm{L}^{-1}$ obteve-se aumento de $0,7 \mathrm{~g}$ na massa fresca da parte aérea, $0,06 \mathrm{~g}$ na massa seca da parte aérea, $0,2 \mathrm{~g}$ na massa fresca das raízes, 0,05 folhas e $0,2 \mathrm{~cm}$ na altura (Figura 1). TRemblay e SenÉCAl (1988) avaliaram duas doses de nitrogênio ( 150 e $350 \mathrm{mg} \mathrm{L}^{-1}$ ) e observaram aumento na área foliar e na massa seca da parte aérea das mudas de alface, porém houve redução na massa seca da raiz. Vital et al. (2002) observaram aumentos nas características das mudas de alface, quando se utilizou adubação com uréia em aplicação foliar e formulado (Peters 9-45-15 e 20-10-20 e Macrofol 8-4410 e 20-10-20) aplicado em fertirrigação. Soundy (1996) avaliou diferentes concentrações de nitrogênio ( 0 até $60 \mathrm{mg} \mathrm{L}^{-1}$ ) e observou maior massa de raiz e parte aérea quanto maior a concentração, sendo mais pronunciado o aumento na parte aérea. Pelos resultados desses autores citados, percebe-se que a parte aérea é mais afetada pela adubação nitrogenada que a raiz, conforme observado neste trabalho. Ainda segundo Soundy (1996), doses elevadas de nitrogênio podem deixar a muda frágil, com dificuldade de recuperação após o transplante. Porém, neste trabalho, as mudas de todos os tratamentos estavam com boa aparência e vigorosas.

A produção de mudas de hortaliças em recipientes necessita de cuidados no manejo com fertilizantes (Soundy, 1996). Quando se utiliza fibra de coco como substrato para produção de mudas, é necessária a aplicação de adubos para que se obtenha maior desenvolvimento das mudas (CARRIJO et al., 2002), devido ao baixo teor de nutrientes. Pelos resultados observados no presente trabalho, percebese que o fornecimento de nitrogênio via fertirrigação favoreceu o maior desenvolvimento das mudas de abobrinha.

As doses de potássio não influenciaram as características avaliadas. No entanto, houve resposta linear do crescimento da parte aérea em função da adubação nitrogenada. 

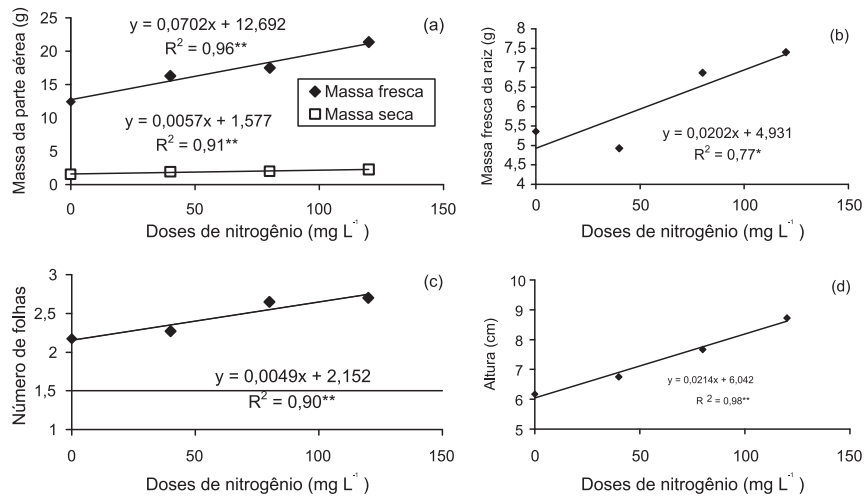

Figura 1. Massa fresca e seca da parte aérea (a); massa fresca da raiz (b); número de folhas (c) e altura (d) das mudas de abóbora; em função das doses de nitrogênio. São Manuel (SP), 2007. Cada símbolo representa o valor de quatro repetições.

\section{REFERÊNCIAS}

CARMELLO, Q.A.C. Nutrição e adubação de mudas hortícolas. In: MINAMI, K. Produção de mudas de alta qualidade em horticultura. São Paulo: T.A. Queiroz, 1995. p.33-37.

CARRIJO, O. A.; LIZ, R. S.; MAKISHIMA, N. Fibra da casca do coco verde como substrato agrícola. Horticultura Brasileira, v.20, p.533-536, 2002.

CORREIA, D.; ROSA, M.F.; NORÕES, E.R.V.; ARAÚJO, F.B. Uso de pó da casca de coco na formulação de substratos para formação de mudas enxertadas de cajueiro anão-precoce. Revista Brasileira de Fruticultura, v.25, p.557-558, 2003.

DUFAULT, R. Relationship among nitrogen, phosphorus, and potassium on celery transplant growth. HortScience, v.20, p.1104-1106, 1985.

ESPINDOLA, C.R.; TOSIN, W.A.C.; PACCOLA, A.A. Levantamento pedológico da Fazenda Experimental São Manuel. In: CONGRESSO BRASILEIRO DE CIÊNCIA DO SOLO, 14., 1974, Santa Maria. Anais... Santa Maria: Sociedade Brasileira de Ciência do Solo, 1974. p.650-654.

FERNANDES, C.; ARAUJO, J. A. C.; CORÁ, J. E. Impacto de quatro substratos e parcelamento da fertirrigação na produção de tomate sob cultivo protegido. Horticultura Brasileira, v.20, p.559-563, 2002.

GOMES, J.M.; SILVA, A.R. Os substratos e sua influência na qualidade de mudas. In: BARBOSA, J.G. (Ed.). Nutrição e adubação de plantas cultivadas em substrato. Viçosa: UFV, 2004. p.190-225.

GONÇALVES, A.R. Substratos para a produção de mudas. In.: MINAMI, K. Produção de mudas de alta qualidade em horticultura. São Paulo: T.A. Queiroz, 1995. p.107-115.

MALAVOLTA, E. Elementos de nutrição mineral de plantas. São Paulo: Ceres, 1980. 251p.
MALAVOLTA, E.; VITTI, G. C.;OLIVEIRA, S. A. Avaliação do estado nutricional de plantas: princípios e aplicações. Piracicaba: Potafos, 1997. 304p.

MALVESTITI, A.L. Propriedades e aplicações da fibra de coco na produção de mudas. In: BARBOSA, J.G. (Ed.). Nutrição e adubação de plantas cultivadas em substrato. Viçosa: UFV, 2004. p.226-235.

MELTON, R.R.; DUFAULT, R.J. Tomato seedling growth, earliness, yield, and quality following pretransplant nutritional conditioning and low temperatures. Journal of American Society for Horticultural Science, v.116, p.421-425, 1991.

SILVEIRA, E. B.; RODRIGUES, V.J.L.B.; GOMES, A.M.A.; MARIANO, R.L.R.; MESQUITA, J.C.P. Pó de coco como substrato para produção de mudas de tomateiro. Horticultura Brasileira, v.20, p.211-216, 2002.

SOUNDY, P. Lettuce transplant root and shoot growth and development in relation to nitrogen, phosphorus, potassium, and water management. 1996. 318p. Tese (PhD), University of Florida, 1996.

SPURR, S.H.; BARNES, B.V. Forest Ecology. New York: Ronald Press, 1973. 571p.

TREMBLAY, N.; SENÉCAL, M. Nitrogen and potassium in nutrient solution influence seedling growth of four vegetables species. HortScience, v.23, p. 1018-1020, 1988.

VITAL, W. M.; TEIXEIRA, N. T.; GALI, M. A.; LIMA, J. G. M.; FERRARO, A. E.; SHIGIHARA, R.; MIGUEL, R. S. Adubação na produção de mudas de alface. Revista Ecossistema, v.27, p.6366, 2002. 